


\title{
PALABRAS DE BIENVENIDA A LA SEGUNDA SEMANA DE LA DIVERSIDAD LINGÜÍSTICA DE COSTA RICA
}

\author{
WELCOME WORDS TO THE SECOND WEEK OF LANGUAGE \\ DIVERSITY IN COSTA RICA
}

\section{Carla Victoria Jara Murillo}

Bienvenidos todos a esta Segunda Semana de la Diversidad Lingüística de Costa Rica.

Como directora del Departamento de Lingüística, para mí es un honor y un orgullo recibirlos en esta actividad, que es la más importante de nuestro departamento en el campo de la acción y la proyección de nuestro quehacer académico.

Este año nos llena de sincera emoción dedicarle la semana al querido maestro Dr. Víctor Manuel Sánchez Corrales.

La Escuela de Filología, Linguiística y Literatura y la Universidad de Costa Rica le deben mucho a don Víctor, y hoy tendremos el gusto de escuchar con detalle sobre sus contribuciones a la lingüística y la educación costarricenses. Quiero aprovechar este momento para decirle a don Víctor, una vez más: gracias, muchas gracias; no solo por sus aportes académicos, que nos han enriquecido y que son muchos, sino por ser la persona que es, el colega, el profesor, el jefe, el amigo.

La Primera Semana de la Diversidad Lingüística de Costa Rica se llevó a cabo en octubre del año 2011. Fue una idea audaz, original, difícil de implementar, por la exigencia de trabajo y entusiasmo que requiere. Esa gran idea fue del Dr. Carlos Sánchez Avendaño, quien como director del Departamento de Lingüística en aquel momento, pensó en la importancia de difundir un hecho que los costarricenses no están siempre dispuestos a reconocer: que este es un país multilingüe y pluricultural, en el que una gran variedad de comunidades distintas coexisten en toda clase de condiciones. Así, tenemos los pueblos talamanqueños: bribris y cabécares; los malecu en el norte; los borucas, térrabas, ngobes y bugles en el sur; tenemos la cultura afrocaribeña y la cultura sorda, cuya lengua es la LESCO, y otros grupos socioculturales

Dra. Carla Victoria Jara Murillo. Universidad de Costa Rica. Directora del Departamento de Lingüística. Costa Rica

Correo electrónico: carla.victoria.jara@gmail.com

Recepción: 16- 01- 2014

Aceptación: 18- 03- 2014 
que si no tienen una lengua diferente, sí tienen sus propias variedades de español, acerca de las cuales vamos a aprender durante esta semana. También hay presencia en nuestro medio de lenguas tan diversas como el esperanto y el latín. Y para cerrar con broche de oro, tendremos oportunidad de echar una mirada al crucial papel que puede jugar la música en la preservación de lenguas en peligro de extinción, como es el caso de la mayoría de las lenguas indígenas.

Y por ayudarnos a conocer y comprender toda esta maravillosa diversidad lingüística que existe en Costa Rica, tengo que darle muy efusivas gracias al Dr. Carlos Sánchez Avendaño.

Quiero agradecer también, a nombre del Departamento, a la Escuela de Filología, Lingüística y Literatura y a su director, Dr. Carlos Villalobos Villalobos, cuyo apoyo ha hecho posible esta actividad. también.

La primera semana fue un éxito rotundo; estoy segura de que la segunda lo será

Muchas gracias a todos por acompañarnos y ique disfruten! 